\title{
Review
}

J. Ginseng Res. Vol. 34, No. 4, 259-263 (2010)

DOI:10.5142/jgr.2010.34.4.259

\section{Panax ginseng: An Overview of the Clinical Evidence}

\author{
Edzard Ernst ${ }^{*}$ \\ Complementary Medicine, Peninsula Medical School, Universities of Exeter \& Plymouth, Exeter EX2 4NT, UK
}

This overview is focused on Panax ginseng, one of the most commonly used herbal remedies. The currently available data regarding its clinical efficacy is somewhat confusing, despite the fact that many clinical trials and systematic reviews have been published. The risks of Panax ginseng seem to be only minor. Numerous mechanisms of action have been described. Future studies of this fascinating herbal remedy seem warranted but they should overcome the methodological limitations of the previous research.

Keywords: Panax ginseng, Herbal medicine, Safety, Efficacy, Evidence

\section{INTRODUCTION}

Ginseng has a long history of medicinal use [1-3]. Today ginseng preparations are amongst the most popular and best-selling herbal medicines worldwide [4]. They are employed for a broad range of conditions - sometimes, sadly, without sufficient proof [5].

A clear distinction between Siberian (sometimes also called Russian) ginseng, Eleutherococcus senticosus, and Asian ginseng, Panax ginseng, is important [6]. The genus Panax includes various species such as Panax quinquefoluis (American ginseng) and Panax japonicus (Japanese ginseng) [4]. The range of ginsenosides contained in Korean Panax ginseng has been reported to be larger than that in other species [7].

In the Korean tradition, several different ways of preparing and manufacturing Panax ginseng exist. Fresh ginseng is less than 4 years old; white ginseng is 4 to 6 years old and is dried after peeling; red ginseng is harvested when it is 6 years old, subsequently it is not skinned but steamed and then dried. The subject is further complicated by the fact that, according to several laboratory investigations, commercially available ginseng products are sometimes of less than optimal quality $[8,9]$. Thus negative trial results could theoretically be due to poor product quality rather than lack of efficacy. The aim of this 'mini-review' is to summarize the existing clinical evidence, mainly based on systematic reviews and metaanalysis, of all types of preparations of Panax ginseng.

\section{HOW TO DETERMINE CLINICAL EFFICACY}

Panax ginseng has been used for medicinal purposes for centuries. One might therefore assume that it has 'stood the test of time' and its therapeutic value is beyond doubt. Yet we know that a long history of use often proves very little. It certainly does not conclusively demonstrate the efficacy nor the safety of the treatment in question.

In order to show efficacy, we require a comparator, i.e., a control group. Without it, one can never be certain whether any observed change in health status after the administration of a therapy is due to the treatment. It might also be caused by a myriad of other factors including natural history of the disease or regression towards the mean. If we want to also exclude placebo-effects and (c) This is an Open Access article distributed under the terms of the Creative Commons Attribution Non-Commercial License (http://creativecommons.org/licenses/by-nc/3.0/) which permits unrestricted non-commercial use, distribution, and reproduction in any medium, provided the original work is properly cited.
Received 16 Jul. 2010, Revised 24 Nov. 2010, Accepted 10 Dec. 2010

* Corresponding author

E-mail: Edzard.Ernst@pms.ac.uk

Tel: +44-1392-424989, Fax: +44-1392-427562 
selection bias, it is best to rely on randomized, placebocontrolled, double-blind clinical trials.

Numerous such studies of Panax ginseng are now available. As their results are not always uniform, it is best to depend not on selected studies, but on the totality of the evidence. This approach of evaluating the evidence is called a systematic review. It entails locating all relevant clinical trials, evaluating them critically and summarizing the overall findings clearly. Under certain circumstances, this can be done by statistically pooling the results from several studies to generate a new, overall, numerical result. This approach to conducting a systematic review is called a meta-analysis.

\section{CLINICAL EFFICACY OF PANAX GINSENG}

In 1999, my team published the first systematic review of ginseng preparations. It included clinical studies of both Panax ginseng and Eleutherococcus senticosus. Five electronic databases were searched for randomized clinical trials (RCTs) that were placebo-controlled and double-blind. We found 16 such studies, most of which tested Panax ginseng for a range of conditions: improvement of physical or psychomotor performance, cognitive function, immunological activity, diabetes, and herpes simplex infections. Regrettably, most of the studies were of poor methodological quality. Because of the paucity and the lack of rigour of the primary data, we had to draw cautious conclusions: "the efficacy of ginseng... is not established... for any... indication" [10]. Since then, many more RCTs and several further systematic reviews have emerged, and the overall picture has become more promising.

In 2003, a team from the US reviewed all 9 clinical trials testing the effects of ginseng on quality of life. The studies turned out to be highly heterogeneous in almost every respect. Even though some of these data were promising, important caveats were noted. The authors therefore concluded that "overall health related quality of life cannot... be attributed to Panax ginseng” [11].

In 2006, US researchers reviewed all RCTs that tested the effects of ginseng on cardiovascular risk factors. They identified 34 studies and found mixed effects on blood lipids and inconsistent effects on blood pressure. They concluded that "current evidence does not support the use of ginseng to treat cardiovascular risk factors" [12].

In 2008, Korean colleagues and I published a systematic review of 'red ginseng' for treating erectile dysfunction. We searched 20 electronic databases and located 7 relevant RCTs. The meta-analysis demonstrated a sig- nificant effect over and above placebo, particularly in a subgroup analysis focussed on psychogenic erectile dysfunction. Unfortunately the methodological quality of all but one study was poor. Thus, our conclusions had to be cautious: "Collectively these RCTs provide suggestive evidence...” [13].

In 2009, Korean colleagues and I published a systematic review of Panax ginseng for the treatment of Alzheimer's disease. We searched 20 databases but found only two RCTs that met our inclusion criteria. The metaanalytic result of these data was positive suggesting that the intake of Panax ginseng improves cognitive function better than placebo. Yet, due to the paucity and the poor methodological quality of the primary studies, we concluded that "the evidence for ginseng as a treatment of Alzheimer's disease is...inconclusive" [14].

In 2009, American authors published a systematic review of all 5 studies testing the value of North American ginseng preparations for preventing the common cold. Collectively these data suggested that, compared to placebo, ginseng intake reduced the number of patients being infected by $25 \%$ and shortened the duration of the condition by 6.2 days. The authors concluded that "North American ginseng appears to be effective in shortening the duration of colds... when taken preventatively for durations of 6 to 16 weeks" [15].

In 2009, Bahrke et al reviewed the studies testing whether ginseng improves athletic performance. They found that most of the trials had serious methodological flaws. Their conclusion was that "enhanced physical performance after ginseng administration in well-designed investigations remains to be demonstrated" [16].

In 2010, Korean colleagues and I published a systematic review of Panax ginseng to treat type II diabetes. We conducted electronic searches in 14 databases and located 6 relevant RCTs. Many of them were less than rigorous. Collectively these studies failed to show effects on glucose metabolism that were different from placebo. We therefore concluded that "the evidence... is largely negative” [17].

Also in 2010, Korean colleagues and I reviewed 5 RCTs testing the potential of Panax ginseng to normalize elevated blood pressure. The results were collectively disappointing but some preliminary evidence emerged to suggest that Korean red ginseng might have an antihypertensive effect [18].

In addition to the conditions covered by these systematic reviews (Table 1), numerous clinical trials and some epidemiological studies have emerged related to indications other than the ones above. Table 2 provides a brief 
Table 1. Systematic reviews of Panax ginseng

\begin{tabular}{|c|c|c|c|}
\hline First author (yr) & Condition & No. of included studies & Main conclusion \\
\hline Vogler (1999) [10] & Any & 16 & Efficacy is not established \\
\hline Coleman (2003) [11] & Quality of life & 9 & Effect uncertain \\
\hline Buettner (2006) [12] & Cardiovascular risk factors & 34 & Inconsistent effects \\
\hline Jang (2008) [13] & Erectile dysfunction & 7 & Suggestive evidence \\
\hline Lee (2009) [14] & Alzheimer's disease & 2 & Inconclusive evidence \\
\hline Seida (2009) [15] & Common cold & 5 & Effective for shortening the duration \\
\hline Bahrke (2009) [16] & Improvement of athletic performance & Unclear & Effect uncertain \\
\hline $\operatorname{Kim}(2010)[17]$ & Type 2 diabetes & 6 & Evidence is largely negative \\
\hline Huh (2010) [18] & Hypertension & 5 & Effect uncertain \\
\hline
\end{tabular}

Table 2. Evidence from non-systematic reviews related to the clinical efficacy of Panax ginseng

\begin{tabular}{ll}
\multicolumn{1}{c}{ Indication } & \multicolumn{1}{c}{ Conclusion (quote) } \\
\hline Cancer [19] & ...research has continually found tumor inhibition \\
Cancer fatigue [20] & There appears to be some activity \\
Menopausal symptoms [21] & There is no convincing evidence \\
Viral myocarditis [22] & ....significant effects on reducing myocardial enzymes and improving cardiac function \\
\hline
\end{tabular}

overview of some of the most important, recent data [19-22].

\section{HOW TO DETERMINE SAFETY}

Clinical trials usually have relative small sample sizes. Thus they normally can only tell us something about common adverse effects but very little about adverse-effects which are not common or rare. Even pooled data from RCT are usually not very informative in this respect, not least because the reporting of adverse effects in clinical trials is often inadequate. In order to reliably assess the safety of medical treatments, it is often necessary to also rely on case reports, case series, post-marketing and other observational studies.

\section{THE SAFETY OF PANAX GINSENG}

In 2002, my team published a systematic review evaluating all the available clinical data relating to safety issues in connection with Panax ginseng [23]. Systematic searches were performed in 5 electronic databases and the reference lists of all papers located were checked for further relevant publications. All articles containing original data on adverse events and drug interactions with Panax ginseng were included. Information was also requested from 12 manufacturers of ginseng preparations, the spontaneous reporting schemes of the World Health Organization and national drug safety bodies.
Data from clinical trials suggested that the incidence of adverse events of ginseng monopreparations is similar to that of placebo. The most commonly experienced adverse events were headache, sleep and gastrointestinal complaints. More serious adverse events emerged in case reports and data from spontaneous reporting schemes. However, causality was often difficult to determine. Combination products containing ginseng as one of several constituents were associated with serious adverse events and even fatalities. Interpretation of these cases is difficult as ingredients other than Panax ginseng may have caused the problems. Drug interactions have been reported between Panax ginseng and warfarin, phenelzine and alcohol.

Collectively, these data suggest that Panax ginseng monopreparations are rarely associated with adverse events or drug interactions. The ones that are documented are usually mild and transient. Combined preparations are more often associated with such events but causal attribution is rarely possible [23]. Because there is a paucity of reliable data, ginseng "should be consumed with caution during pregnancy...and during lactation” [24].

Many investigations have addressed the problem of pesticide residues in herbal materials [5]. These residues were detected both in preparations of Panax notoginseng root, Panax quinquefolium root and Panax ginseng root $[25,26]$. Two recent studies investigated the pesticide residues in 155 medicinal herbal samples (25 species) collected from 11 cultivation bases adhering to 
good clinical practices in Guizhou province. Five kinds of phrethroid pesticides were detected and $14.8 \%$ of all samples were over the legal limit. Above ground parts were more seriously affected than roots [27]. Nine types of organochlorine pesticides were detected and $7.09 \%$ of the samples were over the legal limits. Roots were more seriously affected than the above ground parts [28].

\section{MECHANISMS OF ACTION}

Like all herbal extracts, ginseng preparations are complex mixtures of a range of pharmacologically active ingredients. The most important and best researched, in the case of Panax ginseng, are the ginsenosides, a diverse group of triterpenoidal saponins. About 150 different ginsenosides have so far been identified [29]. These compounds have complex biological activities. The mechanisms of action of Panax ginseng are therefore diverse, complex and often somewhat uncertain (Table 3) [30-38].

\section{IMPLICATIONS FOR FUTURE CLINICAL RE- SEARCH}

The clinical effects of Ginseng have been tested for a wide range of conditions. Yet the collective results have rarely been convincing (Table 1). To a large extent, this is due to the frequently poor quality of the primary studies. All the above-mentioned systematic reviews note that most of the included clinical trials are methodologically flawed [9-17,28]. It follows that, in order to render the findings more conclusive, more rigorous trials are required. Specifically, the following frequent drawbacks should be addressed:

Table 3. Possible mechanisms of action of Panax ginseng

\section{Anti-aptotic effects}

Anti-inflammatory action

Antioxidation

Effects on the hypothalamus-pituitary-adrenal axis

Increase of neural plasticity

Increase of nitric oxide

Modulation of angiogenesis

Modulation of autoimmune transmitter release

Modulation of glucose metabolism

Modulation of ion channels

Modulation of the immune response

Neuroprotective effects

Normalization of lipid profile

Preservation of mitochondrial membrane integrity

Radioprotective effects

Reduction of platelet adhesion

Stimulation of interferon production

Stimulation of natural killer cell activity

Stimulation of phagocytosis

Vasodilatation
- Reporting of the trials must be improved and should adhere to accepted guidelines, e.g., CONSORT.

- A full description of the tested ginseng preparation should be included.

- Treatment periods should be of sufficient length.

- Adverse effects should be reported in full detail.

- Sample sizes should be adequate and based on power calculations.

- Outcome measures should be validated.

- Correct statistical analyses must be employed.

- Conclusions must be cautious and based on the data.

- Generally speaking, all details need to be published such that the reader is able to replicate the study.

\section{CONCLUSION}

Panax ginseng is a popular herbal medicine used worldwide for a broad range of indications. Many clinical trials and systematic reviews are now available. Their conclusions vary but, for some indications, they are encouraging. Future clinical research in this area should aim at overcoming the methodological limitations of much of the previous research.

\section{REFERENCES}

1. Lü JM, Yao Q, Chen C. Ginseng compounds: an update on their molecular mechanisms and medical applications. Curr Vasc Pharmacol 2009;7:293-302.

2. Jia L, Zhao Y. Current evaluation of the millennium phytomedicine--ginseng (I): etymology, pharmacognosy, phytochemistry, market and regulations. Curr Med Chem 2009;16:24752484.

3. Xiang YZ, Shang HC, Gao XM, Zhang BL. A comparison of the ancient use of ginseng in traditional Chinese medicine with modern pharmacological experiments and clinical trials. Phytother Res 2008;22:851-858.

4. Ernst E. The risk-benefit profile of commonly used herbal therapies: Ginkgo, St. John's wort, ginseng, Echinacea, saw palmetto, and kava. Ann Intern Med 2002;136:42-53.

5. Heavey S. Herbs, supplements often sold deceptively: U.S. report. Available from: http://http://www.reuters.com/article/idUSTRE64P5MY20100526.

6. Chen CF, Chiou WF, Zhang JT. Comparison of the pharmacological effects of Panax ginseng and Panax quinquefolium. Acta Pharmacol Sin 2008;29:1103-1108.

7. Choi KT. Botanical characteristics, pharmacological effects and medicinal components of Korean Panax ginseng C. A. Meyer. Acta Pharmacol Sin 2008;29:1109-1118.

8. ConsumerLab.com. Product review: ginseng supplements. 
Available from: https://www.consumerlab.com/reviews/ ginseng_supplements/ginseng/.

9. Sievenpiper JL, Arnason JT, Vidgen E, Leiter LA, Vuksan $\mathrm{V}$. A systematic quantitative analysis of the literature of the high variability in ginseng (Panax spp.): should ginseng be trusted in diabetes? Diabetes Care 2004;27:839-840.

10. Vogler BK, Pittler MH, Ernst E. The efficacy of ginseng. A systematic review of randomised clinical trials. Eur J Clin Pharmacol 1999;55:567-575.

11. Coleman CI, Hebert JH, Reddy P. The effects of Panax ginseng on quality of life. J Clin Pharm Ther 2003;28:515.

12. Buettner C, Yeh GY, Phillips RS, Mittleman MA, Kaptchuk TJ. Systematic review of the effects of ginseng on cardiovascular risk factors. Ann Pharmacother 2006;40:83-95.

13. Jang DJ, Lee MS, Shin BC, Lee YC, Ernst E. Red ginseng for treating erectile dysfunction: a systematic review. Br J Clin Pharmacol 2008;66:444-450.

14. Lee MS, Yang EJ, Kim JI, Ernst E. Ginseng for cognitive function in Alzheimer's disease: a systematic review. J Alzheimers Dis 2009;18:339-344.

15. Seida JK, Durec T, Kuhle S. North American (Panax quinquefolius) and Asian ginseng (Panax ginseng) preparations for prevention of the common cold in healthy adults: a systematic review. Evid Based Complement Alternat Med 2009; Epub ahead of print.

16. Bahrke MS, Morgan WP, Stegner A. Is ginseng an ergogenic aid? Int J Sport Nutr Exerc Metab 2009;19:298-322.

17. Kim S, Lee MS, Shin BC, Sim H, Ernst E. Red ginseng for treating type 2 diabetes mellitus: a systematic review and meta-analysis. submitted.

18. Huh MH, Lee MS, Kim C, Ernst E. Ginseng for the treatment of hypertension: a systematic review. J Ginseng Res 2010;34:342-347.

19. Helms S. Cancer prevention and therapeutics: Panax ginseng. Altern Med Rev 2004;9:259-274.

20. Barton DL, Soori GS, Bauer BA, Sloan JA, Johnson PA, Figueras C, Duane S, Mattar B, Liu H, Atherton PJ, et al. Pilot study of Panax quinquefolius (American ginseng) to improve cancer-related fatigue: a randomized, doubleblind, dose-finding evaluation: NCCTG trial N03CA. Support Care Cancer 2010;18:179-187.

21. Huntley AL, Ernst E. A systematic review of herbal medicinal products for the treatment of menopausal symptoms. Menopause 2003;10:465-476.

22. Liu JP, Yang M, Du XM. Herbal medicines for viral myocarditis. Cochrane Database Syst Rev 2004;(3):CD003711.

23. Coon JT, Ernst E. Panax ginseng: a systematic review of adverse effects and drug interactions. Drug Saf 2002;25:323344.
24. Seely D, Dugoua JJ, Perri D, Mills E, Koren G. Safety and efficacy of Panax ginseng during pregnancy and lactation. Can J Clin Pharmacol 2008;15:e87-e94.

25. Chen C, Xiao YP, Song YQ. Investigation and analysis of organochlorine pesticide residues in traditional Chinese medicinal. J Shaanxi Norm Univ. Natural sciences edition 2006; 34:264-271.

26. Li LL, Yuan WJ, Zhang SL. Analysis of organochlorine pesticide residues in the imported American ginseng and Senna. Zhong Cao Yao 2003;34:610.

27. Xia PH, Zhang MS, Chen WS, Wu Q. Pyrethroid pesticide residues in medicianl plants in Guizhou GAP bases. Lishizhen Med \& Materia Med Res 2008;19:3010-3012.

28. Zhang MS, Zhang ZK, Xia PH. Investigation on the organochlorine pesticides residues in Chinese herbal materials from Guizhou GAP bases. Shenyang Yao Ke Da Xue Xue Bao 2009;26:473-476.

29. Christensen LP. Ginsenosides chemistry, biosynthesis, analysis, and potential health effects. Adv Food Nutr Res 2009; 55:1-99.

30. Kiefer D, Pantuso T. Panax ginseng. Am Fam Physician 2003;68:1539-1542.

31. Zhou W, Chai H, Lin PH, Lumsden AB, Yao Q, Chen CJ. Molecular mechanisms and clinical applications of ginseng root for cardiovascular disease. Med Sci Monit 2004;10: RA187-RA192.

32. Sengupta S, Toh SA, Sellers LA, Skepper JN, Koolwijk P, Leung HW, Yeung HW, Wong RN, Sasisekharan R, Fan TP. Modulating angiogenesis: the yin and the yang in ginseng. Circulation 2004;110:1219-1225.

33. Cabral de Oliveira AC, Perez AC, Prieto JG, Duarte ID, Alvarez AI. Protection of Panax ginseng in injured muscles after eccentric exercise. J Ethnopharmacol 2005;97:211-214.

34. Jia L, Zhao Y, Liang XJ. Current evaluation of the millennium phytomedicine-ginseng (II): collected chemical entities, modern pharmacology, and clinical applications emanated from traditional Chinese medicine. Curr Med Chem 2009;16:2924-2942.

35. Rausch WD, Liu S, Gille G, Radad K. Neuroprotective effects of ginsenosides. Acta Neurobiol Exp (Wars) 2006; 66:369-375

36. Lee TK, Johnke RM, Allison RR, O’Brien KF, Dobbs LJ Jr. Radioprotective potential of ginseng. Mutagenesis 2005;20:237-243.

37. Cheng Y, Shen LH, Zhang JT. Anti-amnestic and antiaging effects of ginsenoside Rg1 and Rb1 and its mechanism of action. Acta Pharmacol Sin 2005;26:143-149.

38. Radad K, Gille G, Liu L, Rausch WD. Use of ginseng in medicine with emphasis on neurodegenerative disorders. J Pharmacol Sci 2006;100:175-186. 